\title{
Production and Purification of a Novel Xanthan Lyase from a Xanthan-Degrading Microbacterium sp. Strain XT11
}

\author{
Fan Yang, Lan Yang, Xiaoyu Guo, Xue Wang, Lili Li, Zhicheng Liu, \\ Wei Wang, and Xianzhen Li \\ School of Biological Engineering, Dalian Polytechnic University, Ganjingqu, Dalian 116034, China \\ Correspondence should be addressed to Xianzhen Li; xianzhen@mail.com
}

Received 27 January 2014; Revised 2 June 2014; Accepted 4 June 2014; Published 26 June 2014

Academic Editor: Argyro Bekatorou

Copyright (c) 2014 Fan Yang et al. This is an open access article distributed under the Creative Commons Attribution License, which permits unrestricted use, distribution, and reproduction in any medium, provided the original work is properly cited.

\begin{abstract}
A xanthan lyase was produced and purified from the culture supernatant of an excellent xanthan-modifying strain Microbacterium sp. XT11. Xanthan lyase was induced by xanthan but was inhibited by its structural monomer glucose. Its production by strain XT11 is much higher than that by all other reported strains. The purified xanthan lyase has a molecular mass of $110 \mathrm{kDa}$ and a specific activity of $28.2 \mathrm{U} / \mathrm{mg}$ that was much higher than that of both Paenibacillus and Bacillus lyases. It was specific on the pyruvated mannosyl residue in the intact xanthan molecule, but about $50 \%$ lyase activity remained when xanthan was partially depyruvated. Xanthan lyase was optimally active at $\mathrm{pH} 6.0-6.5$ and $40^{\circ} \mathrm{C}$ and alkali-tolerant at a high $\mathrm{pH}$ value of 11.0. The metal ions including $\mathrm{K}^{+}, \mathrm{Ca}^{2+}, \mathrm{Na}^{+}, \mathrm{Mg}^{2+}, \mathrm{Mn}^{2+}$, and $\mathrm{Li}^{+}$strongly stimulated xanthan lyase activity but ions $\mathrm{Zn}^{2+}$ and $\mathrm{Cu}^{2+}$ were its inhibitor. Xanthan lyase should be a novel enzyme different from the other xanthan lyases ever reported.
\end{abstract}

\section{Introduction}

Xanthan is an important anionic heteropolysaccharide produced by Xanthomonas campestris pv. campestris and contains a cellulosic backbone with the mannosyl-glucuronylmannosyl side chain linked to an alternated glucosyl residue at C-3 position (Figure 1) $[1,2]$. The inner mannosyl residues are acetylated and the terminal mannosyl residues are pyruvated in the side chain depending on the xanthan-producing strains and culture condition $[3,4]$. Such structure makes xanthan have peculiar rheological properties, leading to a wide application in the industrial process as a thickener, gelling agent or stabilizer of emulsion and dispersion $[1,2,5]$.

It has been demonstrated that the truncation of the side chain in xanthan molecule could result in some benefits from a scientific or practical point of view. The removal of the mannosyl residue in the terminal side chains could result in weaker viscosifier injected into the underground oil bearing formation [6]. The cut-off of both the terminal mannosyl and the glucuronyl residues produces a viscosifier superior to xanthan [7]. Furthermore, elicitor-active oligosaccharides produced from xanthan with the truncated side chain could block the formation of black rot lesions on cruciferous plants by inhibiting $X$. campestris pv. campestris $[8,9]$.

The variant xanthan with the truncated side chain could be produced by $X$. campestris mutants $[7,10]$, whereas its production level is far from what is required for practical use [11]. Therefore, because of the molecular design of xanthan, the use of relevant enzymes seems to be a preferable and promising way to obtain a tailor-made xanthan with specific and desired properties [12]. Differing from other polysaccharide lyases acting on the polysaccharide backbone, xanthan lyase could cleave the linkage between the terminal mannosyl and the glucuronyl residues on the side chain by a $\beta$-elimination reaction, introducing a double bond between $\mathrm{C} 4$ and $\mathrm{C} 5$ of the uronosyl residue and subsequently might be exploited for further chemical modification [13]. However, xanthan lyase was purified from both Paenibacillus alginolyticus XL-1 and Bacillus sp. GL1 so far [14, 15], in which the production of xanthan lyase was too low to meet the demand for the structural modification of xanthan.

In our previous work, an excellent xanthan-degrading bacterium Microbacterium sp. XT11 was isolated [9], which produced high activity of extracellular xanthan-degrading 


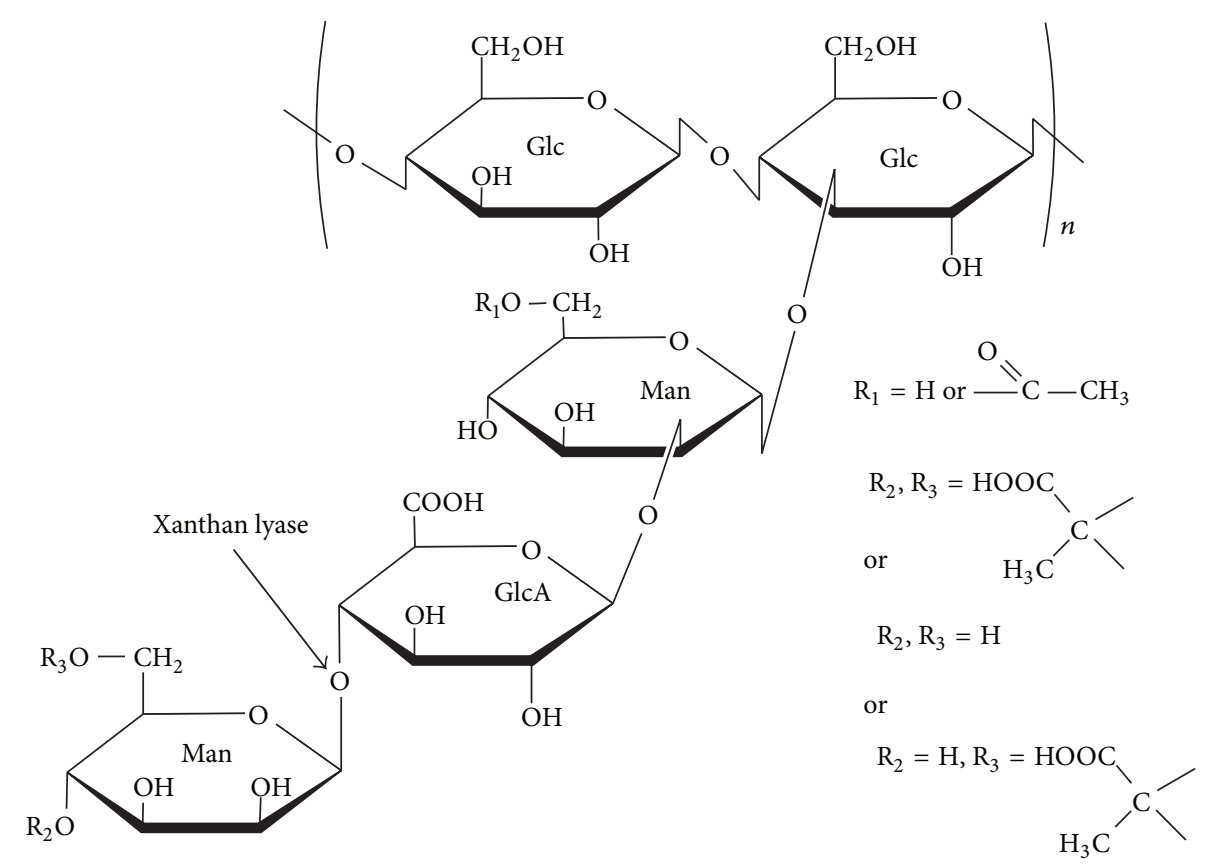

Figure 1: Chemical structure of xanthan. The cleavage site for xanthan lyase is indicated by solid arrows. Glc, D-glucose; Man, D-mannose; GlcA, D-glucuronic acid.

enzymes and could efficiently fragment xanthan to form the bioactive oligosaccharide $[8,9]$. The endoxanthanase cleaving the backbone linkage of the xanthan has been purified [8], whereas the xanthan lyase was not characterized and the way to modify the terminal side chains of xanthan remained unclear. In this paper, the xanthan lyase produced by Microbacterium sp. XT11 was purified and characterized. It is valuable for modifying xanthan molecules to extend its application in oil enhancing recovery and bioactive oligosaccharide production.

\section{Materials and Methods}

2.1. Microorganism. Microbacterium sp. XT11 was isolated from soil for xanthan degradation in our lab and cultured in the xanthan medium at $30^{\circ} \mathrm{C}$ as described elsewhere [9]. The xanthan medium consists of (per liter) $3 \mathrm{~g}$ xanthan and $3 \mathrm{~g}$ yeast extract in the mineral salt solution, $\mathrm{pH}$ 7.0. The mineral salt solution contains (per liter) $50 \mathrm{mg} \mathrm{K}_{2} \mathrm{HPO}_{4}$, $800 \mathrm{mg} \mathrm{NaCl}, 25 \mathrm{mg} \mathrm{MgSO}_{4} \cdot 7 \mathrm{H}_{2} \mathrm{O}$, and $700 \mathrm{mg} \mathrm{KNO}$.

2.2. Optimum Culture Condition and Xanthan Lyase Production. The influence of carbon source on xanthan lyase production was performed by incubating the strain XT11 in the mineral salt solution ( $\mathrm{pH} 7.0$ ) supplemented with $0.3 \%$ yeast extract and $0.3 \%$ different carbohydrates including xanthan, glucose, sucrose, fructose, starch, and xanthan plus $0.2 \%$ glucose at $30^{\circ} \mathrm{C}$ and $150 \mathrm{rpm}$. The relationship between the nitrogen source and xanthan lyase production was determined by culturing the strain XT11 in the mineral salt solution ( $\mathrm{pH} 7.0$ ) with $0.3 \%$ xanthan and varied nitrogen sources including $0.3 \%$ yeast extract, peptone, ammonium sulfate, tryptone, and corn extract, respectively. The optimal $\mathrm{pH}$ for the production of xanthan lyase was evaluated in the xanthan medium at $\mathrm{pH}$ range of 2.0-10.0.

To determine the time-course of the strain XT11 cultured in the xanthan medium, samples were collected every $6 \mathrm{~h}$ to measure cell growth and xanthan lyase activity, in which the xanthan lyase was determined in the supernatant after centrifugation at $10,000 \mathrm{~g}$ and $4^{\circ} \mathrm{C}$ for $30 \mathrm{~min}$. All the experiments were performed thrice.

In total, $5 \mathrm{~L}$ of the xanthan medium distributed in ten $2 \mathrm{~L}$ flasks was inoculated with the overnight culture of Microbacterium sp. XT11 at a ratio of 1:50. After incubation for $18 \mathrm{~h}$ the supernatant was obtained by centrifuging the culture at $10,000 \mathrm{~g}$ and $4^{\circ} \mathrm{C}$ for $30 \mathrm{~min}$ and used for enzyme purification.

2.3. Purification of Xanthan Lyase. A representative process for the purification of xanthan lyase was carried out as follows. All operations were performed at $4^{\circ} \mathrm{C}$ unless otherwise specified.

(i) Ammonium sulfate fractionation: the culture supernatant was adjusted to $\mathrm{pH} 6.0$ and centrifuged at 10,000 g for $30 \mathrm{~min}$. Ammonium sulfate was added portion-wise to a final concentration of $30-60 \%$ saturation, and the mixture was gently stirred overnight. The suspension was centrifuged at $10,000 \mathrm{~g}$ for $30 \mathrm{~min}$. The recovered precipitate was dissolved in $20 \mathrm{mM}$ potassium phosphate buffer (KPB) at $\mathrm{pH} 6.0$ and dialyzed against the same buffer with three changes of the buffer, which was used as the crude enzyme solution.

(ii) Hydrophobic interaction chromatography: to the crude enzyme solution, solid $\left(\mathrm{NH}_{4}\right)_{2} \mathrm{SO}_{4}$ was added to a final concentration of $0.8 \mathrm{M}$. After being filtered through a 
$0.22 \mu \mathrm{m}$ durapore membrane (Millipore Corporation, USA), the enzyme solution was passed through a hydrophobic interaction chromatography (HIC) column packed with $5 \mathrm{~mL}$ phenyl Sepharose resin (GE Healthcare, Sweden) previously equilibrated with $20 \mathrm{mM} \mathrm{KPB}$ at $\mathrm{pH}$ 6.0. Protein was eluted with a linear gradient of 0.8 to $0 \mathrm{M}\left(\mathrm{NH}_{4}\right)_{2} \mathrm{SO}_{4}$ in $20 \mathrm{mM} \mathrm{KPB}$ $(\mathrm{pH} 6.0)$ at a flow rate of $2.0 \mathrm{~mL} / \mathrm{min}$ in a total volume of $50 \mathrm{~mL}$. The fractions were collected and protein was detected by UV light absorption at $280 \mathrm{~nm}$. The active xanthan lyase fractions were pooled and dialyzed overnight at $4^{\circ} \mathrm{C}$ against 20 mM KPB (pH 6.0).

(iii) Anion-exchange chromatography: the HIC pool was applied to an anion-exchange chromatography (AEC) column (5 mL Q Sepharose FF resin, GE Healthcare, Sweden). Protein was eluted with a linear gradient of 0 to $1.0 \mathrm{M} \mathrm{NaCl}$ in $20 \mathrm{mM} \mathrm{KPB}(\mathrm{pH} 6.0)$ at a flow rate of $1 \mathrm{~mL} / \mathrm{min}$ in a total volume of $50 \mathrm{~mL}$. Xanthan lyase-containing fractions were pooled and concentrated using a stirred ultrafiltration cell (Millipore Corporation, USA) over a 10-KDa molecular weight cut-off membrane.

For every purification step, fractions containing the target protein were determined by SDS-PAGE analysis.

2.4. Characterization of Xanthan Lyase. To assess the temperature optimum for xanthan lyase activity, $V_{\max }$ was determined by Lineweaver-Burk plot in $100 \mathrm{mM}$ phosphate buffer $(\mathrm{pH} 6.0)$ at different temperatures ranging from $20^{\circ} \mathrm{C}$ to $70^{\circ} \mathrm{C}$ [16]. The thermostability of xanthan lyase was determined by assaying the $V_{\max }$ after the xanthan lyase was incubated in $100 \mathrm{mM}$ phosphate buffer ( $\mathrm{pH} 6.0)$ at various temperatures $\left(20-60^{\circ} \mathrm{C}\right)$ for $30 \mathrm{~min}$. The optimal $\mathrm{pH}$ for xanthan lyase activity was assayed by calculating the $V_{\max }$ from LineweaverBurk plot in $100 \mathrm{mM}$ phosphate buffer at different $\mathrm{pH}$ [16]. To measure the $\mathrm{pH}$ stability, $V_{\max }$ assays were performed using the enzyme sample that was preincubated at different $\mathrm{pH}$ for $2 \mathrm{~h}$.

Under the optional temperature and $\mathrm{pH}$ condition, the enzyme activity was measured with the addition of $10 \mathrm{mM}$ different metal ions, including $\mathrm{K}^{+}, \mathrm{Ca}^{+}, \mathrm{Na}^{+}, \mathrm{Mg}^{2+}, \mathrm{Zn}^{2+}$, $\mathrm{Cu}^{2+}, \mathrm{Mn}^{2+}$, and $\mathrm{Li}^{+}$in the reaction system, respectively. All experiments were done in triplicate.

2.5. SDS-PAGE Analysis. The sodium dodecyl sulfatepolyacrylamide gel electrophoresis (SDS-PAGE) was carried out as follows. Aliquots of the protein samples purified at different stages were loaded onto the stacking gel contained $5 \%$ polyacrylamide and separated in the resolving gel contained $12 \%$ polyacrylamide. Protein was visualized by coomassie brilliant blue R-250 or silver staining.

\subsection{Purification and Chemical Modification of Substrate} Xanthan. Xanthan was purified as described previously [17]. Briefly, the food-grade xanthan was dissolved in the distilled water and diluted to $1 \mathrm{~g} / \mathrm{L}$. Xanthan was precipitated by adding the equal volume of ice-cold absolute ethanol in the presence of $\mathrm{NaCl}(100 \mathrm{~g} / \mathrm{L})$ after stirring for $2 \mathrm{~h}$ at $4^{\circ} \mathrm{C}$. The precipitate was collected by filtration and washed with ethanol-water mixture up to $100 \%$ in ethanol. The purified xanthan was lyophilized for the following test.

The chemical modification of xanthan was performed using the following procedures. The solution containing $5 \mathrm{~g} / \mathrm{L}$ of the purified xanthan in $5 \mathrm{mM}$ trifluoroacetic acid was heated at $100^{\circ} \mathrm{C}$ for $1.5 \mathrm{~h}$ to remove the pyruvic acetyl groups [18]. The purified xanthan $(2.5 \mathrm{~g} / \mathrm{L})$ in $0.1 \mathrm{M} \mathrm{NH}_{4} \mathrm{OH}$ was incubated at $60^{\circ} \mathrm{C}$ for $1 \mathrm{~h}$ to remove the acetyl groups [19]. Both the depyruvated and the deacetylated xanthan were dialyzed against the distilled water and lyophilized, respectively.

2.7. Enzyme Assay. All assays were done in triplicates, and the mean values were presented.

The activity of xanthan lyase was assayed in the reaction mixture containing $0.5 \mathrm{mg} / \mathrm{mL}$ of the purified xanthan in $100 \mathrm{mM}$ potassium phosphate buffer $(\mathrm{pH}$ 6.0) and appropriately diluted xanthan lyase. After incubation at $40^{\circ} \mathrm{C}$ for $10 \mathrm{~min}$, the increase in the absorbance at $235 \mathrm{~nm}$ was determined. Appropriate controls for the absorbance decrease with addition of the heated xanthan lyase $\left(100^{\circ} \mathrm{C}, 5 \mathrm{~min}\right)$ were included. One unit of xanthan lyase activity was defined as the amount of enzyme that produced an increase of 1.0 in the absorbance at $235 \mathrm{~nm}$ per min under the above condition.

2.8. Chemical Analysis. The acetyl content of xanthan was measured according to the method of Hestrin [20] with acetylcholine as a reference. To determine the pyruvate content of xanthan, $0.01 \mathrm{~g}$ xanthan was hydrolyzed in $5 \mathrm{~mL} \mathrm{HCl}$ $(1 \mathrm{M})$ at $100^{\circ} \mathrm{C}$ for $3 \mathrm{~h}$, and the free pyruvate was determined as described by Sloneker and Orentas [21] with sodium pyruvate as the reference. Protein concentration was measured using the Bio-Rad protein assay kit (Bio-Rad, USA). Cell growth was determined by optical density (O.D.) at $600 \mathrm{~nm}$.

\section{Results}

3.1. Production of Xanthan Lyase by Microbacterium sp. $X T 11$. The effect of carbon sources and nitrogen sources on the production of xanthan lyase was determined as shown in Figure 2. The highest xanthan lyase activity was obtained when xanthan was used as carbon source, while much lower titers of xanthan lyase were produced with all other tested carbohydrates (Figure $2(\mathrm{a})$ ). When $0.2 \%$ glucose was supplemented in the xanthan medium, less than $60 \%$ activity remained. The maximal activity of xanthan lyase was detected in the xanthan medium with yeast extract as nitrogen source compared with the other tested nitrogen sources (Figure 2(b)). Almost no xanthan lyase activity could be detected when ammonium sulfate or corn extract was used as nitrogen source, and only about $25 \%$ enzyme activity was obtained in the xanthan medium with peptone or tryptone as nitrogen source.

The influence of the initial $\mathrm{pH}$ in the xanthan medium on xanthan lyase production was shown in Figure 3. The maximal enzyme activity was detected when strain XT11 was cultured in the xanthan medium at $\mathrm{pH}$ range of 6.0-8.0. No xanthan lyase activity could be detected in the culture 


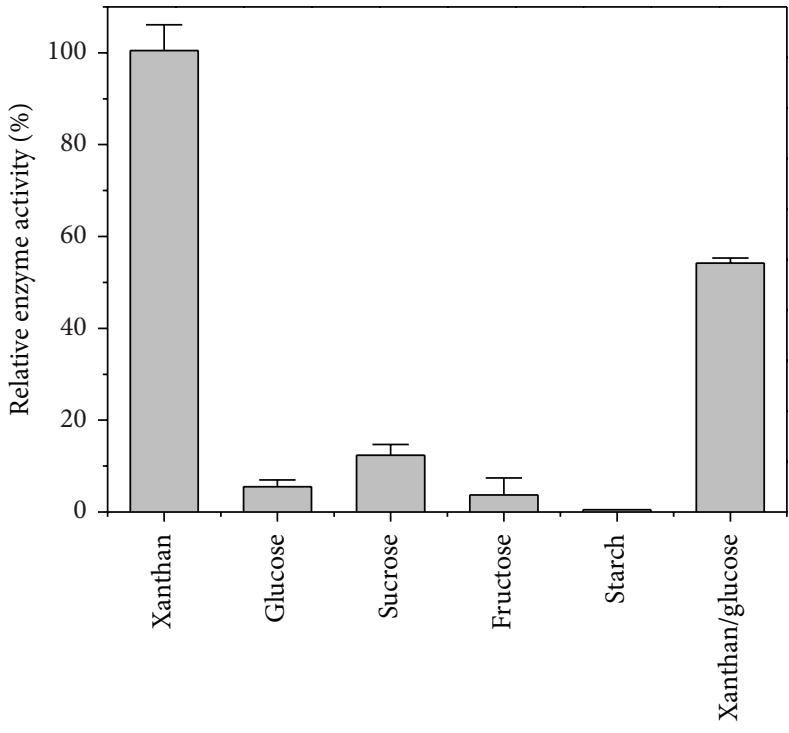

(a)

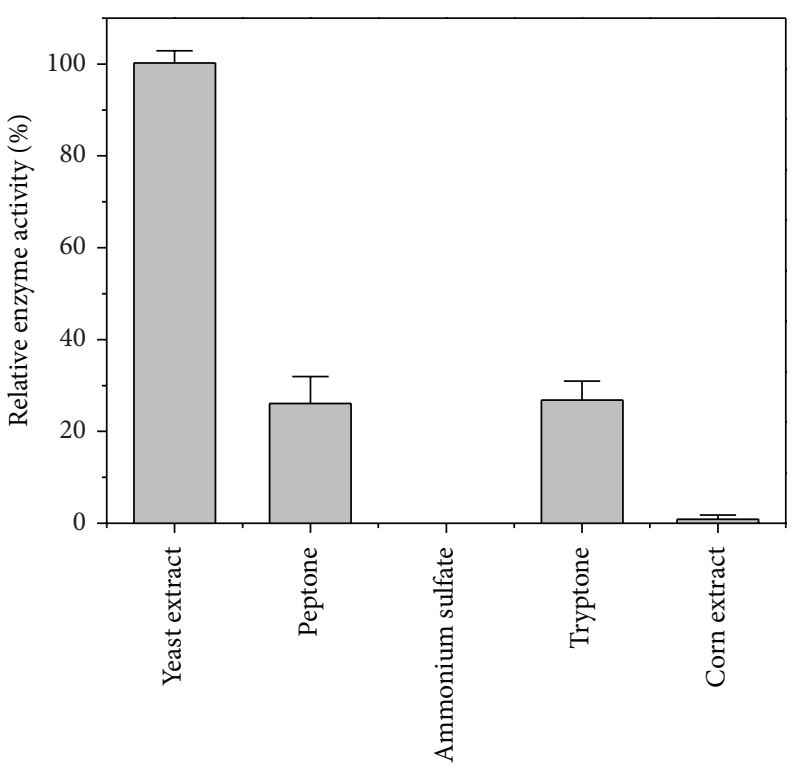

(b)

FIGURE 2: Xanthan lyase production when Microbacterium sp. XT11 was cultured in the medium with different carbon sources (a) and various nitrogen sources (b) shaking at $30^{\circ} \mathrm{C}$.

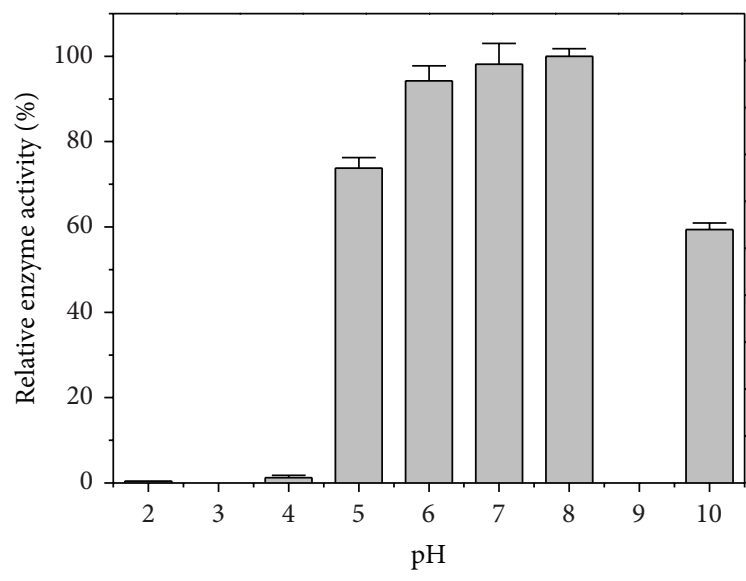

FIGURE 3: Influence of initial $\mathrm{pH}$ on xanthan lyase production by Microbacterium sp. XT11 cultured in the xanthan medium at $30^{\circ} \mathrm{C}$ and $150 \mathrm{rpm}$.

fluid of Microbacterium sp. XT11 when the initial pH of the xanthan medium was lower than $\mathrm{pH} 4.0$, but more than $60 \%$ enzyme activity was obtained even though the strain XT11 was incubated at $\mathrm{pH} 10.0$.

The time-course of cell growth and xanthan lyase production was shown in Figure 4. In the case that $0.3 \%$ xanthan was used as carbon source, the maximum enzyme activity $(2.43 \pm 0.05 \mathrm{U} / \mathrm{mL})$ was obtained after the strain XT11 was cultured for $18 \mathrm{~h}$, whereas the enzyme activity was decreased significantly when the culture time was extended from $18 \mathrm{~h}$ to $48 \mathrm{~h}$. The $\mathrm{OD}_{600 \mathrm{~nm}}$ tended to be stable and not to be increased obviously after the strain XT11 was cultured for $18 \mathrm{~h}$.

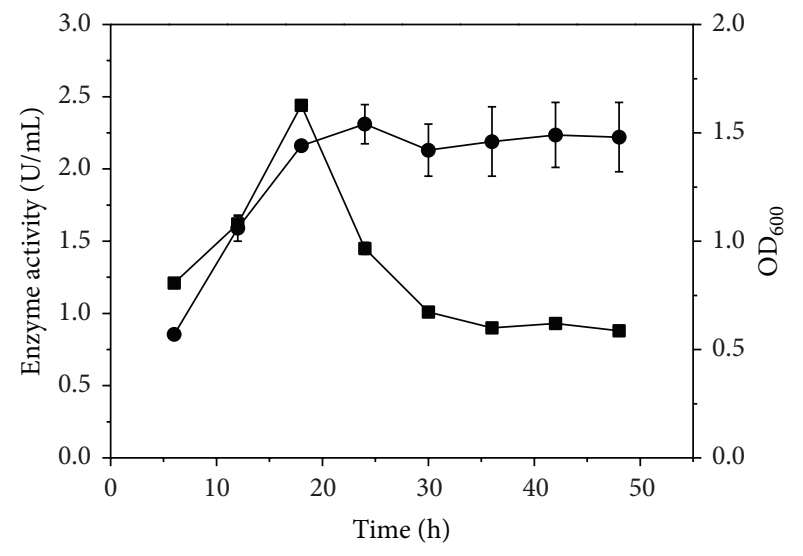

FIGURE 4: Time-course of cell growth (๑) and xanthan lyase activity (घ) when Microbacterium sp. XT11 was cultured in $0.3 \%$ xanthan medium at $30^{\circ} \mathrm{C}$ and shaking at $150 \mathrm{rpm}$.

Therefore, the culture supernatant harvested at $18 \mathrm{~h}$ was ready for the subsequent purification of xanthan lyase.

3.2. Purification of Xanthan Lyase. Purification was performed from the cell-free culture broth of Microbacterium sp. XT11 with a specific activity of $2.2 \mathrm{U} / \mathrm{mg}$. The results were summarized in Table 1 . In the first step, ammonium sulfate precipitation gave a sample of $2.7 \mathrm{U} / \mathrm{mg}$ with a protein recovery of $75.6 \%$. When the crude enzyme solution was applied on the HIC column, the protein containing xanthan lyase was eluted from the phenyl Sepharose column at approximately $0.2 \mathrm{M}\left(\mathrm{NH}_{4}\right)_{2} \mathrm{SO}_{4}$ in one fraction. After being dialyzed against $20 \mathrm{mM} \mathrm{KPB}$, the HIC pool was applied to 
TABLE 1: Purification of xanthan lyase from the xanthan-grown culture of Microbacterium sp. XT11.

\begin{tabular}{|c|c|c|c|c|c|}
\hline Purification steps & Lyase activity (U) & Total protein content $(\mathrm{mg})$ & Specific activity (U/mg) & $\begin{array}{c}\text { Yield } \\
\%\end{array}$ & Purification fold \\
\hline Cell-free culture broth & 253.3 & 115 & 2.2 & 100 & 1 \\
\hline$\left(\mathrm{NH}_{4}\right)_{2} \mathrm{SO}_{4}$ precipitation & 191.4 & 71.3 & 2.7 & 75.6 & 1.2 \\
\hline Phenyl Sepharose & 150.3 & 28.4 & 5.3 & 59.3 & 2.4 \\
\hline Q Sepharose FF & 126.7 & 4.5 & 28.2 & 50.4 & 12.8 \\
\hline
\end{tabular}

TABLE 2: Influence of metal ions on xanthan lyase activity. The assays were performed at $40^{\circ} \mathrm{C}$ and $\mathrm{pH} 6.5$ and the residual enzyme activity was expressed as the percentage against a control without metal ion addition.

\begin{tabular}{lccccccccc}
\hline Ions & Control & $\mathrm{K}^{+}$ & $\mathrm{Ca}^{2+}$ & $\mathrm{Na}^{+}$ & $\mathrm{Mg}^{2+}$ & $\mathrm{Zn}^{2+}$ & $\mathrm{Cu}^{2+}$ & $\mathrm{Mn}^{2+}$ & $\mathrm{Li}^{+}$ \\
\hline Relative activity (\%) & 100 & 196.3 & 194.4 & 192.1 & 186.6 & 53.5 & 19.0 & 152.6 & 191.7 \\
\hline
\end{tabular}

Q Sepharose FF column and the enzyme fraction was eluted at $0.3 \mathrm{M} \mathrm{NaCl}$. The preparation gave a total protein recovery of $50.4 \%$ in a purification fold of 12.8 , and the final product had a specific activity of $28.2 \mathrm{U} / \mathrm{mg}$. As shown in Figure 5(a), samples from each purification step were analyzed by SDSPAGE stained with coomassie brilliant blue and the impurities were gradually removed in the purification processes. To confirm the purity of xanthan lyase, the silver staining of the gel containing the purified enzyme was performed as shown in Figure 5(b).

3.3. Enzymatic Properties of Xanthan Lyase. The molecular mass of the xanthan lyase purified from Microbacterium sp. XT11 was $110 \mathrm{kDa}$ as determined by both SDS-PAGE (Figure 5) and gel permeation chromatography (Sephacryl S200HR) (data not shown).

The xanthan lyase was active at temperature ranging from $20^{\circ} \mathrm{C}$ to $40^{\circ} \mathrm{C}$, while almost no activity could be detected at $50^{\circ} \mathrm{C}$. The maximum $V_{\max }$ was observed at $40^{\circ} \mathrm{C}$ (Figure $6(\mathrm{a})$ ). Xanthan lyase was relatively stable at temperature below $40^{\circ} \mathrm{C}$, as high $V_{\max }$ was observed when the enzyme was incubated at selected temperatures for $30 \mathrm{~min}$ (Figure 6(a)). The xanthan lyase showed the highest $V_{\max }$ at $\mathrm{pH}$ range of 6.0-6.5 but reduced substantially beyond this $\mathrm{pH}$ range (Figure 6(b)). The enzyme was stable when the samples were held at $\mathrm{pH}$ range of 5.5-11.0 for $2 \mathrm{~h}$ (Figure 6(b)). The xanthan lyase activity was detected in the presence of different metal ions. As shown in Table 2, the xanthan lyase activity was significantly enhanced by the metal ions including $\mathrm{K}^{+}, \mathrm{Ca}^{2+}$, $\mathrm{Na}^{+}, \mathrm{Mg}^{2+}, \mathrm{Mn}^{2+}$, and $\mathrm{Li}^{+}$but was intensely inhibited by $\mathrm{Zn}^{2+}$ and almost completely inhibited by metal ion $\mathrm{Cu}^{2+}$. The xanthan lyase exhibited a typical Michaelis-Menten kinetics, and the values of $K_{m}$ and $V_{\max }$ for xanthan were $4.23 \mathrm{mg} / \mathrm{mL}$ and $8.22 \mu \mathrm{mol} / \mathrm{L} / \mathrm{min}$, respectively, under the optimal $\mathrm{pH}$ and temperature conditions.

To examine the substrate specificity, xanthan lyase was incubated at $40^{\circ} \mathrm{C}$ for $10 \mathrm{~min}$ in the mixture containing $100 \mathrm{mM}$ potassium phosphate buffer ( $\mathrm{pH}$ 6.0) and various substrates. The lyase activity could be detected in the reaction system with xanthan as enzymatic substrate, but there was no activity found when the other polysaccharides including alginate, heparin, hyaluronan, and pectin were used as
TABLE 3: Influence of the various xanthan on activities of xanthan lyase produced by Microbacterium sp. XT11.

\begin{tabular}{lccc}
\hline Xanthan samples & $\begin{array}{c}\text { Acetylation } \\
(\%)\end{array}$ & $\begin{array}{c}\text { Pyruvation } \\
(\%)\end{array}$ & $\begin{array}{c}\text { Relative } \\
\text { activity }(\%)\end{array}$ \\
\hline Native & 9.7 & 15.3 & 100 \\
Acetate-free & 0 & 16.2 & 94.5 \\
Pyruvate-free & 10.2 & 8.0 & 48.8 \\
Pyruvate-/acetate- & 0 & 8.7 & 47.9 \\
free & & \\
\hline
\end{tabular}

substrate. To determine the effect of the pyruvyl and acetyl group on xanthan lyase activity, the crude xanthan substrate was purified and the acetylation and pyruvation extent of xanthan was determined as $9.7 \%$ and $15.3 \%$ respectively. All the acetyl groups could be removed when xanthan was deacetylated, and only a half of the pyruvic groups in xanthan were removed by depyruvation treatment (Table 3 ). As shown in Table 3, the xanthan lyase activity toward native xanthan and acetate-free xanthan was much higher than that toward the pyruvate-free xanthan and pyruvate/acetate-free xanthan.

\section{Discussion}

The truncation of the side chain had a dramatic effect on the viscometric properties of xanthan [22]. However, those tailormade xanthans with different truncated side chains are produced at low yield by genetic engineering mutants [11]. Therefore, the enzymatic modification on the side chain is expected to be a preferable method to obtain such truncated xanthan with different physicochemical and physiological functions for specific purpose [12]. So far, an important xanthanmodifying enzyme, xanthan lyase, has been obtained from xanthan-degrading strains $P$. alginolyticus XL-1 and Bacillus sp. GL1 $[14,15]$. However, the results showed that their xanthan lyase production was greatly decreased when the xanthan-degrading strains were purified from the mixed cultures they originated from $[23,24]$. To overcome such a reduction in lyase production, a novel xanthan-degrading strain Microbacterium sp. XT11 was isolated in our lab [9]. One of the xanthanase (endo-1,4- $\beta$-D-glucanase) catalyzing 


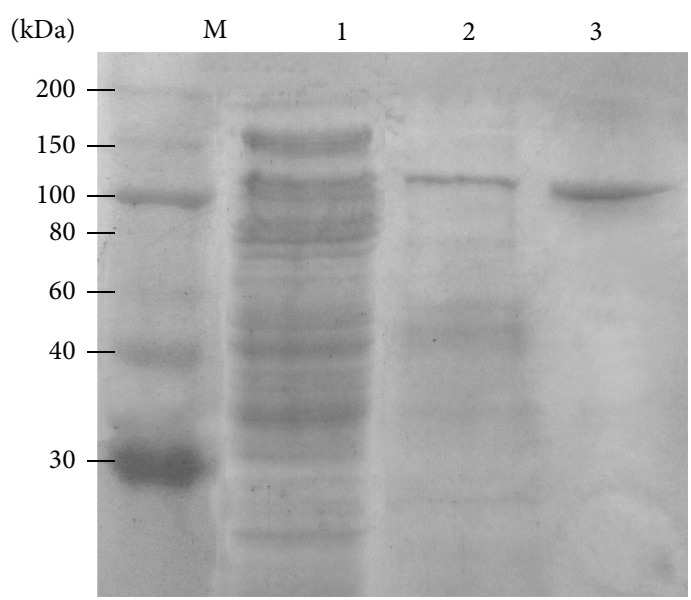

(a)

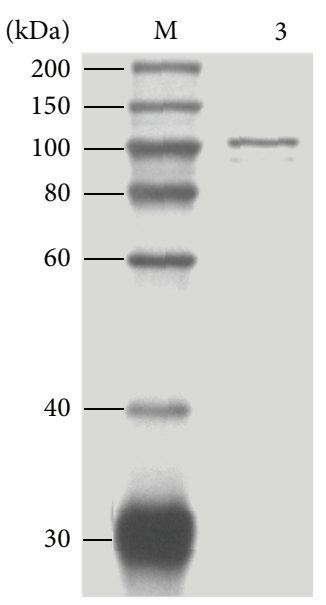

(b)

FIGURE 5: SDS-PAGE analysis of the samples from various steps of xanthan lyase purification by staining with coomassie brilliant blue (a) and the purified xanthan lyase by silver staining (b). Lane 1: ammonium sulfate precipitation sample; lane 2: the eluted protein solution after the phenyl Sepharose column; lane 3: the final xanthan lyase product after the Q Sepharose FF column; and lane M: the protein marker.

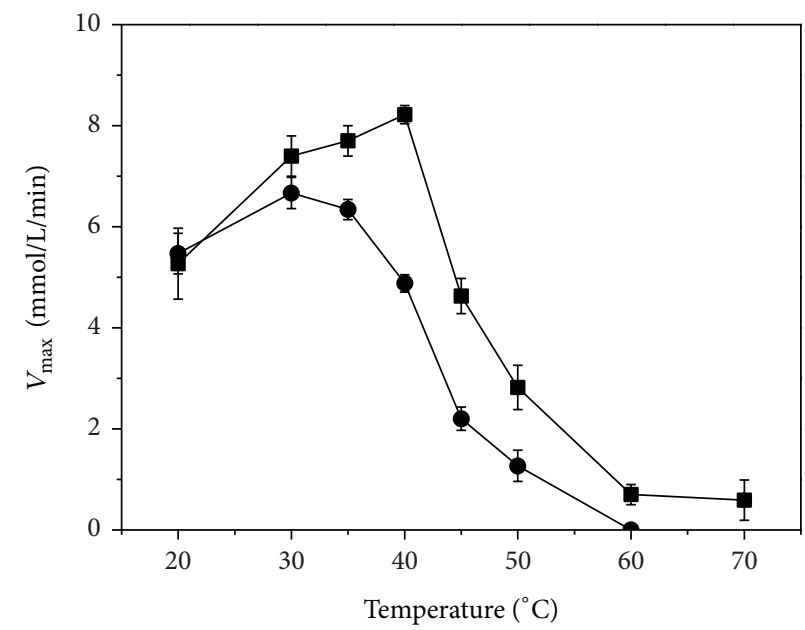

(a)

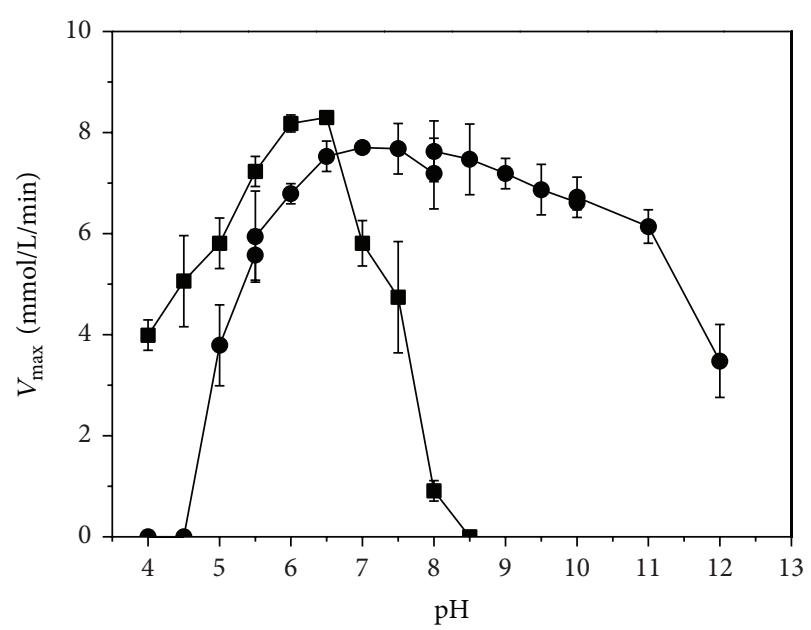

(b)

FIGURE 6: $V_{\max }$ determined from Lineweaver-Burk plot as a function of temperature (a) and $\mathrm{pH}$ (b) for the reaction of Microbacterium sp. $\mathrm{XT11}$ xanthan lyase with xanthan as substrate. The temperature/pH optimum was symbolized as " $\square$ " and the thermostability/pH stability was marked as "

the hydrolysis of the main chain of xanthan has been purified with a high specific activity [8]. All results suggested that the strain XT11 was a potential powerful tool for xanthan modification $[8,9,25]$. However, as an important xanthanmodifying enzyme, xanthan lyase has not been characterized yet, resulting in the application in truncation xanthan to be still in its infancy.

The production and characterization of xanthan lyase were studied in this paper. The data in Figure 2(a) showed a xanthan induction of xanthan lyase in Microbacterium sp. XT11. Furthermore, a decreased production of xanthan lyase was observed when glucose was used together with xanthan as carbon source, suggesting that the structural monomer of xanthan showed a repressive activity against its induction of xanthan lyase. It is unbelievable that the xanthan lyase production was induced by xanthan because it is too large to enter a bacterial cell. However, the similar result was obtained in the production of xanthan lyase by $P$. alginolyticus $\mathrm{XL}-1$, in which the enzymatic degradation intermediate was presumed as the true xanthan lyase inducer [15]. Such an intermediate presumably is from the side chain of xanthan because $\beta$-1,4-glucan backbone remained intact in the culture of $P$. alginolyticus XL-1 [15].

The xanthan lyase was purified from the culture supernatant by a three-step procedure including ammonium sulfate precipitation, hydrophobic chromatography, and Q anion-exchange chromatography. The purified xanthan lyase is significantly different from the reported xanthan lyases in molecular size and belongs to the large polysaccharide lyase family, the molecular mass $(110 \mathrm{kDa})$ of which is much 
larger than the reported enzymes with molecular mass at the range of 75 to $85 \mathrm{kDa}$ in this group $[14,15]$. A large xanthan lyase with $97-\mathrm{kDa}$ was also obtained from Escherichia coli transformed with xalB gene of Bacillus sp. GL1, while it was converted to a low-molecular-mass enzyme $(75-\mathrm{kDa})$ after storage at $4^{\circ} \mathrm{C}$ [26]. It was suggested that the xanthan lyase in Bacillus sp. GL1 is first secreted as a precursor $(97 \mathrm{kDa})$ and then processed into a mature form $(75 \mathrm{kDa})$ through excision of a C-terminal protein fragment with a molecular mass of $22 \mathrm{kDa}$ [26], whereas such maturation could not be found in the culture of Microbacterium sp. XT11. The gene cloning of xanthan lyase is being processed to understand such a difference and its favored effect in xanthan modification. However, it is not easy to amplify this gene from Microbacterium sp. XT11 with a high GC content (69\%) and an unclear genetic background, although about 40 entries for xanthan lyase proteins were found in NCBI database.

There was no significant difference in the optimal $\mathrm{pH}$ for xanthan lyase activity between the lyase from strain XT11 and other reported enzymes $[14,15]$. The xanthan lyase was stable over a wide $\mathrm{pH}$ range, and about $90 \%$ of its total activity remained even after the lyase was held at $\mathrm{pH} 11.0$ for $2 \mathrm{~h}$, which is significantly different from other reported lyases [14] and similar to alkaliphilic alginate lyase from Saccharophagus sp. Myt-1 [27]. Different from Bacillus lyase being affected slightly by metal ions [14], the activity of xanthan lyase from strain XT11 was strongly enhanced by all tested metal ions except $\mathrm{Zn}^{2+}$ and $\mathrm{Cu}^{2+}$. The ion $\mathrm{Cu}^{2+}$ showed almost complete inhibition on xanthan lyase from strain XT11, while causing a 70\% Paenibacillus enzyme activity drop [15]. In particular, the production of xanthan lyase by strain XT11 $(2.2 \mathrm{U} / \mathrm{mg})$ was much higher than that by other two reported xanthan-degrading strains $(0.134 \mathrm{U} / \mathrm{mg}$ for Bacillus sp. GL1 and $0.10 \mathrm{U} / \mathrm{mg}$ for $P$. alginolyticus XL-1) [14, 15], indicating that the pure Microbacterium strain was competent for xanthan modification. Furthermore, the xanthan lyase from Microbacterium sp. XT11 had a higher specific activity $(28.2 \mathrm{U} / \mathrm{mg})$ in contrast with the reported data $(6.28 \mathrm{U} / \mathrm{mg}$ for the Bacillus enzyme and $2.62 \mathrm{U} / \mathrm{mg}$ for the Paenibacillus enzyme) $[14,15]$.

Like the xanthan lyases produced by Paenibacillus and Bacillus [14, 15], Microbacterium xanthan lyase was active on the intact xanthan and was not associated with endoglucanase [8]. Thus, its true substrate probably is the intact xanthan rather than the xanthan-derived oligosaccharides. The xanthan lyase activity toward the depyruvated xanthan was significantly lower than that toward the native xanthan (Table 3), suggesting that the Microbacterium xanthan lyase was specific for pyruvated mannosyl residues. This finding is similar to the enzymes described by Ruijssenaars et al. [12] and Hashimoto et al. [26]. However, about half of the activity was detected when the depyruvated xanthan was used as substrate to measure the xanthan lyase from Microbacterium sp. XT11. This result is comparable with the fact that only a half of pyruvyl residual in xanthan molecule was removed in the acidic treatment (Table 3 ), which was mild to prevent the cleavage of glycosidic bonds. It is different from the Paenibacillus lyase that is not active on the partially depyruvated xanthan [15]. It is clear that the Microbacterium enzyme prefers pyruvated xanthan to nonpyruvated xanthan. As shown in Table 3, the acetyl group in xanthan molecules has no effect on xanthan lyase activity.

\section{Conclusions}

A xanthan lyase was produced and purified from the xanthandegrading Microbacterium sp. XT11, which is the large polysaccharide lyase. The Microbacterium xanthan lyase was produced maximally when xanthan was used as carbon source, while its production was inhibited by glucose. The xanthan lyase has a higher specific activity and was stable at a wider $\mathrm{pH}$ range of 5.5-11.0. Most of the tested metal ions strongly stimulated xanthan lyase activity but ions $\mathrm{Zn}^{2+}$ and $\mathrm{Cu}^{2+}$ were its inhibitor. Xanthan lyase from Microbacterium sp. XT11 was specific on the pyruvated mannosyl residue in the intact xanthan molecules but about 50\% lyase activity remained when xanthan was partially depyruvated. All data suggested that the xanthan lyase was a novel enzyme differing from the other xanthan lyases ever reported.

\section{Conflict of Interests}

The authors declare that there is no conflict of interests regarding the publication of this paper.

\section{Acknowledgments}

Financial support provided by Natural Sciences Foundation of China (31201302 and 31371742), Special Fund for Agroscientific Research in the Public Interest (201303095), Science and Technology Department of Dalian (2013B11NC078 and 2012J21DW009), and Education Department of Liaoning (L2012197) is greatly acknowledged.

\section{References}

[1] A. L. Savvides, E. A. Katsifas, D. G. Hatzinikolaou, and A. D. Karagouni, "Xanthan production by Xanthomonas campestris using whey permeate medium," World Journal of Microbiology and Biotechnology, vol. 28, no. 8, pp. 2759-2764, 2012.

[2] L. Xu, G. Xu, T. Liu, Y. Chen, and H. Gong, "The comparison of rheological properties of aqueous welan gum and xanthan gum solutions," Carbohydrate Polymers, vol. 92, no. 1, pp. 516-522, 2013.

[3] W. Hashimoto, H. Nankai, B. Mikami, and K. Murata, "Crystal structure of Bacillus sp. GL1 xanthan lyase, which acts on the side chains of xanthan," The Journal of Biological Chemistry, vol. 278, no. 9, pp. 7663-7673, 2003.

[4] H. Nankai, W. Hashimoto, and K. Murata, "Molecular identification of family $38 \alpha$-mannosidase of Bacillus sp. strain GL1, responsible for complete depolymerization of xanthan," Applied and Environmental Microbiology, vol. 68, no. 6, pp. 2731-2736, 2002.

[5] M. Khalil and B. Mohamed Jan, "Herschel-Bulkley rheological parameters of a novel environmentally friendly lightweight biopolymer drilling fluid from xanthan gum and starch," Journal of Applied Polymer Science, vol. 124, no. 1, pp. 595-606, 2012. 
[6] S. Levy, S. C. Schuyler, R. K. Maglothin, and L. Andrew Staehelin, "Dynamic simulations of the molecular conformations of wild type and mutant xanthan polymers suggest that conformational differences may contribute to observed differences in viscosity," Biopolymers, vol. 38, no. 2, pp. 251-272, 1996.

[7] R. A. Hassler and D. H. Doherty, "Genetic engineering of polysaccharide structure: production of variants of xanthan gum in Xanthomonas campestris," Biotechnology Progress, vol. 6, no. 3, pp. 182-187, 1990.

[8] B. Li, J. Guo, W. Chen et al., "Endoxanthanase, a novel $\beta$-dGlucanase hydrolyzing backbone linkage of intact xanthan from newly isolated Microbacterium sp. XT11," Applied Biochemistry and Biotechnology, vol. 159, no. 1, pp. 24-32, 2009.

[9] F. Qian, L. An, M. Wang, C. Li, and X. Li, "Isolation and characterization of a xanthan-degrading Microbacterium sp. strain XT11 from garden soil," Journal of Applied Microbiology, vol. 102, no. 5, pp. 1362-1371, 2007.

[10] M. I. Tait and I. W. Sutherland, "Synthesis and properties of a mutant type of xanthan," Journal of Applied Microbiology, vol. 66, no. 5, pp. 457-460, 1989.

[11] R. W. Vanderslice, D. H. Doherty, M. A. Capage et al., "Genetic engineering of polysaccharide structure in Xanthomonas campestris," in Biomedical and Biotechnological Advances in Industrial Polysaccharides, V. Crescenzi, I. C. M. Dea, S. Paoletti, S. S. Stivala, and I. W. Sutherland, Eds., pp. 145156, Gordon and Breach, New York, NY, USA, 1989.

[12] H. J. Ruijssenaars, S. Hartmans, and J. C. Verdoes, "A novel gene encoding xanthan lyase of Paenibacillus alginolyticus strain XL1," Applied and Environmental Microbiology, vol. 66, no. 9, pp. 3945-3950, 2000.

[13] X. Li and X. Chen, "Biodegradation of polysaccharide sourced from virulence factor or plant and pathogenic cell wall constituent and its application in management of phytopathogenic disease," in Environmental Biodegradation Research, B. Y. Wang, Ed., pp. 1-47, Nova Science Publishers, New York, NY, USA, 2007.

[14] W. Hashimoto, H. Miki, N. Tsuchiya, H. Nankai, and K. Murata, "Xanthan lyase of Bacillus sp. strain GL1 liberates pyruvylated mannose from xanthan side chains," Applied and Environmental Microbiology, vol. 64, no. 10, pp. 3765-3768, 1998.

[15] H. J. Ruijssenaars, J. A. M. de Bont, and S. Hartmans, "A pyruvated mannose-specific xanthan lyase involved in xanthan degradation by Paenibacillus alginolyticus XL-1," Applied and Environmental Microbiology, vol. 65, no. 6, pp. 2446-2452, 1999.

[16] G. N. Wilkinson, "Statistical estimations in enzyme kinetics," The Biochemical Journal, vol. 80, pp. 324-332, 1961.

[17] F. Callet, M. Milas, and M. Rinaudo, "Influence of acetyl and pyruvate contents on rheological properties of xanthan in dilute solution," International Journal of Biological Macromolecules, vol. 9, no. 5, pp. 291-293, 1987.

[18] I. J. Bradshaw, B. A. Nisbet, M. H. Kerr, and I. W. Sutherland, "Modified xanthan-its preparation and viscosity," Carbohydrate Polymers, vol. 3, no. 1, pp. 23-38, 1983.

[19] K. P. Shatwell, I. W. Sutherland, I. C. M. Dea, and S. B. RossMurphy, "The influence of acetyl and pyruvate substituents on the helix-coil transition behaviour of xanthan," Carbohydrate Research, vol. 206, no. 1, pp. 87-103, 1990.

[20] S. Hestrin, "The reaction of acetylcholine and other carboxylic acid derivatives with hydroxylamine, and its analytical application," Journal of Biological Chemistry, vol. 180, no. 1, pp. 249-261, 1949.
[21] J. H. Sloneker and D. G. Orentas, "Pyruvic acid, a unique component of an exocellular bacterial polysaccharide," Nature, vol. 194, no. 4827, pp. 478-479, 1962.

[22] L. Wang, F. Zhu, Q. Yang, and D. Lu, "Rheological properties of modified xanthan and their influence on printing performances on cotton with reactive dyes in screen printing," Cellulose, vol. 20, no. 4, pp. 2125-2135, 2013.

[23] M. C. Cadmus, L. K. Jackson, and K. A. Burton, "Biodegradation of xanthan gum by Bacillus sp," Applied and Environmental Microbiology, vol. 44, no. 1, pp. 5-11, 1982.

[24] M. C. Cadmus, M. E. Slodki, and J. J. Nicholson, "Hightemperature, salt-tolerant xanthanase," Journal of Industrial Microbiology, vol. 4, no. 2, pp. 127-133, 1989.

[25] H. Liu, C. Huang, W. Dong, Y. Du, X. Bai, and X. Li, "Biodegradation of xanthan by newly isolated Cellulomonas sp. LX, releasing elicitor-active xantho-oligosaccharides-induced phytoalexin synthesis in soybean cotyledons," Process Biochemistry, vol. 40, no. 12, pp. 3701-3706, 2005.

[26] W. Hashimoto, H. Miki, N. Tsuchiya, H. Nankai, and K. Murata, "Polysaccharide lyase: molecular cloning, sequencing, and overexpression of the xanthan lyase gene of Bacillus sp. strain GL1," Applied and Environmental Microbiology, vol. 67, no. 2, pp. 713-720, 2001.

[27] A. Sakatoku, D. Tanaka, and S. Nakamura, "Purification and characterization of an alkaliphilic alginate lyase AlgMytC from Saccharophagus sp. Myt-1," Journal of Microbiology and Biotechnology, vol. 23, no. 6, pp. 872-877, 2013. 

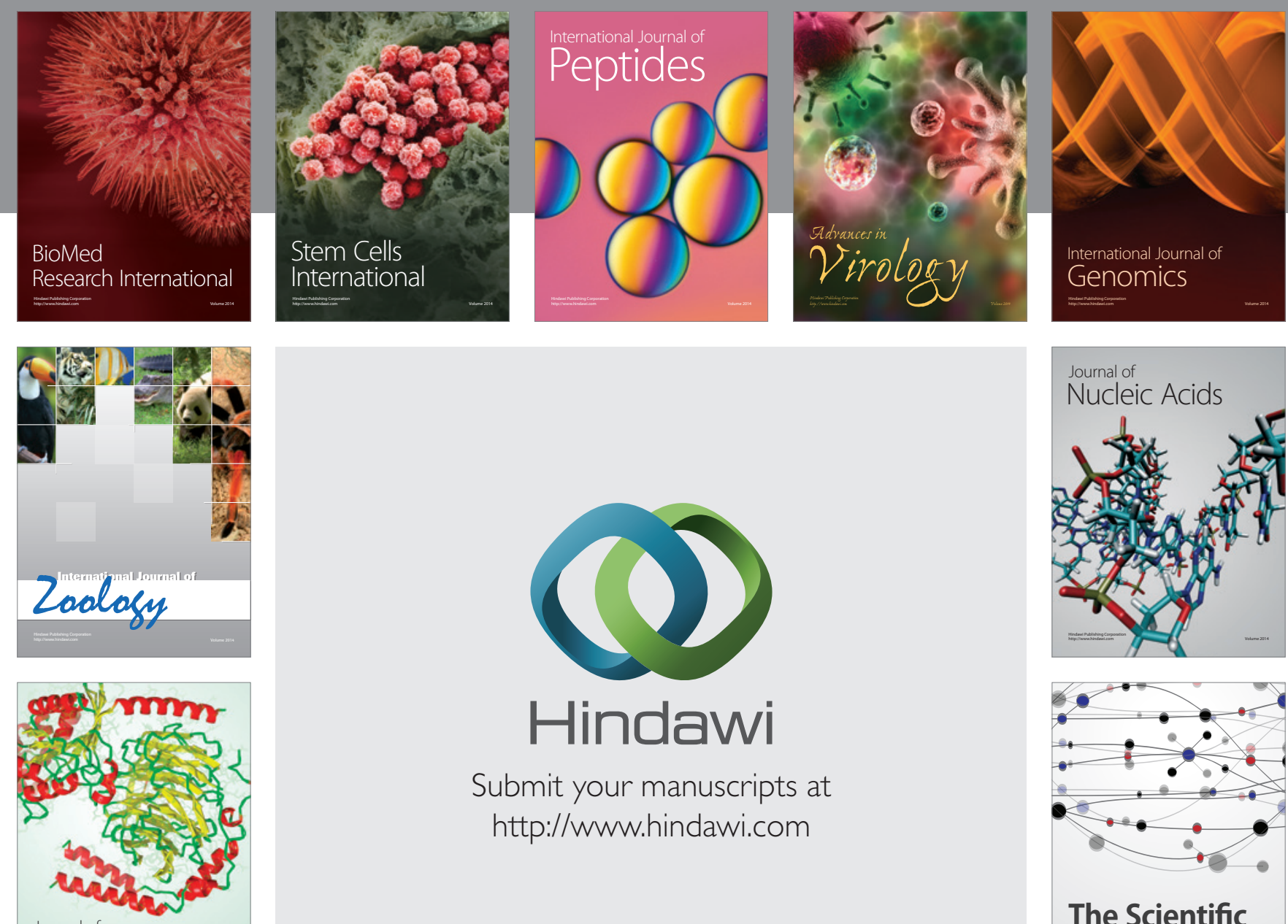

Submit your manuscripts at

http://www.hindawi.com

Journal of
Signal Transduction
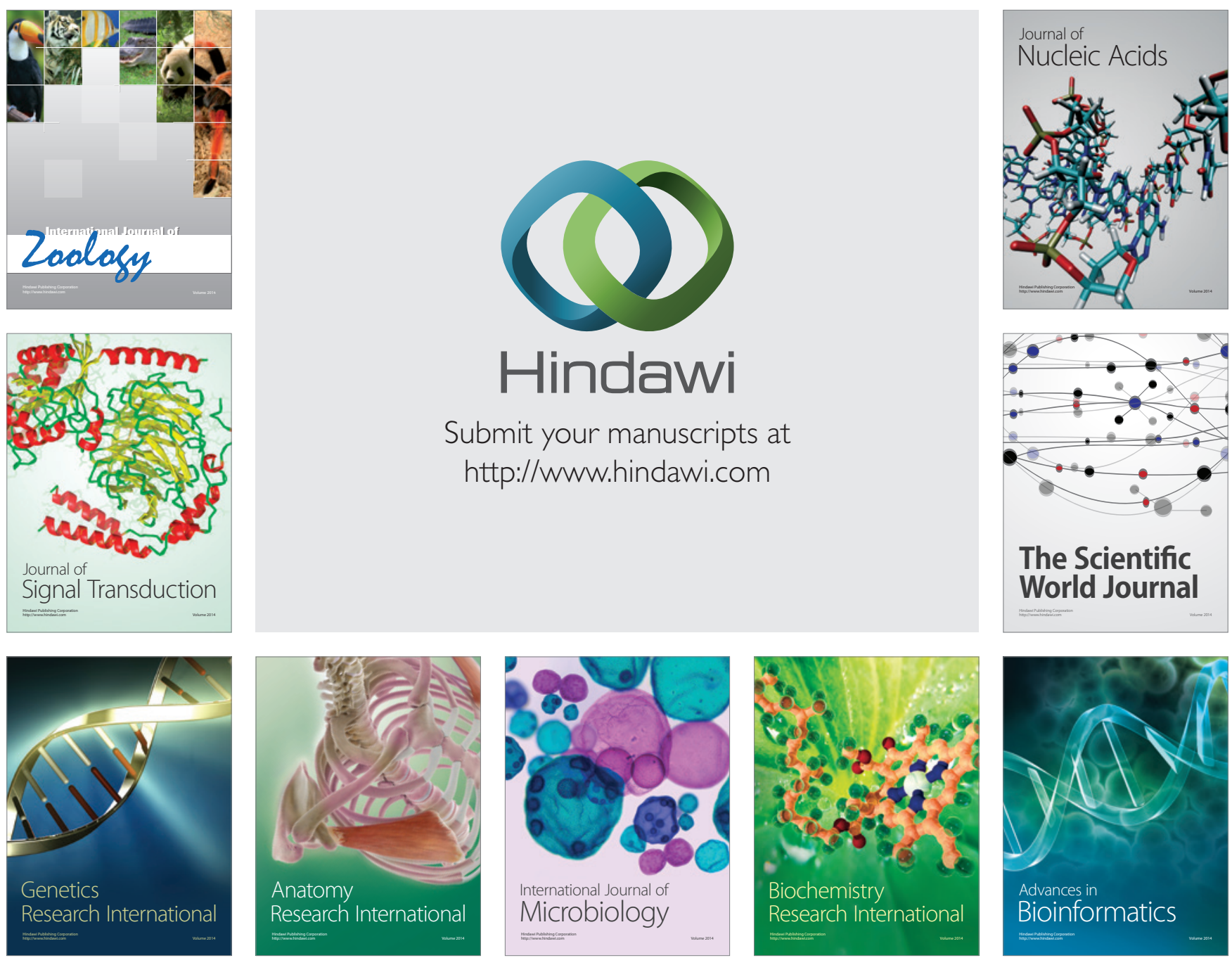

The Scientific World Journal
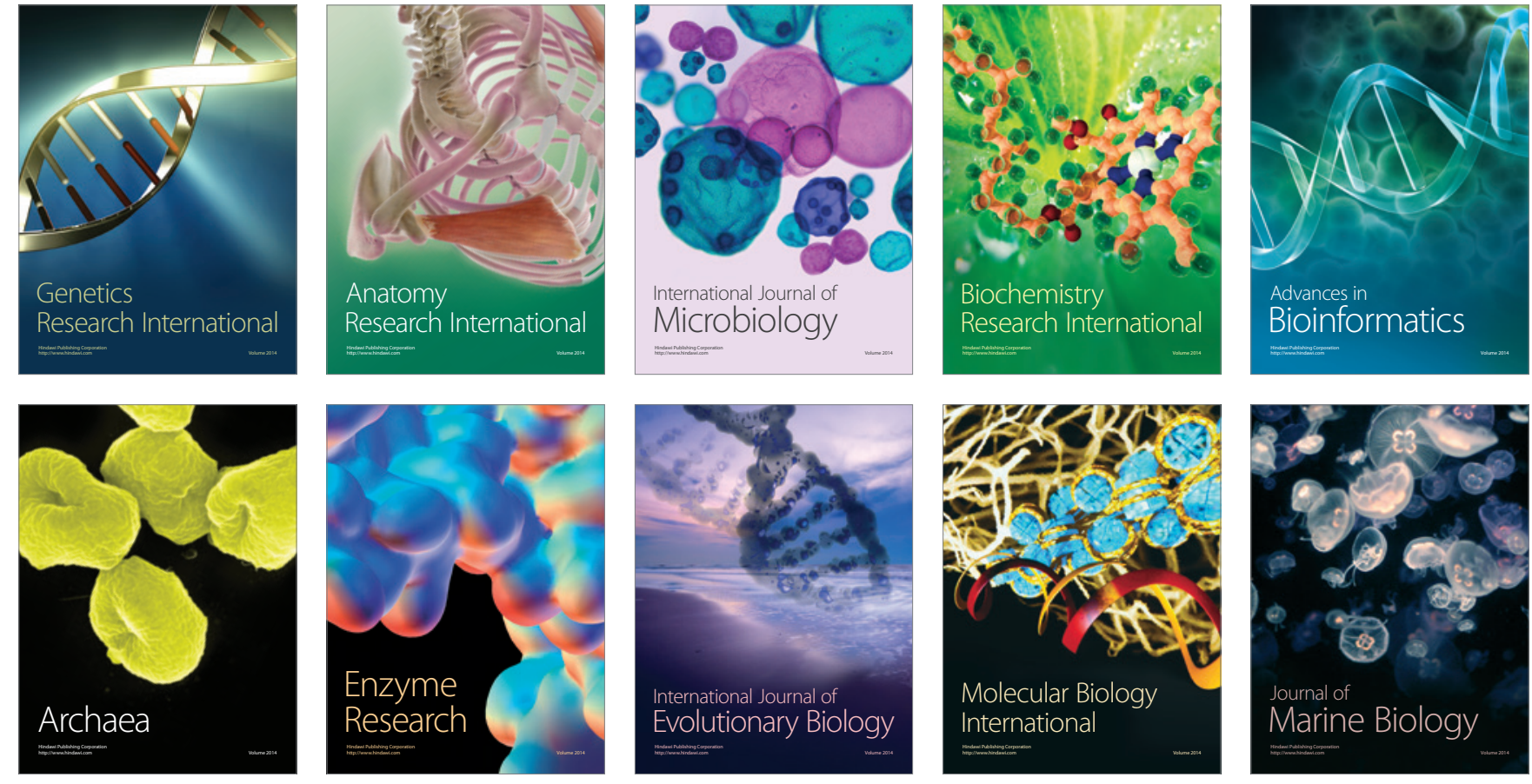